\title{
A Cross Sectional Study of Perception of First Year Medical Students Students on Different Teaching Methods
}

\author{
Dr. Shashiraj $\mathrm{HK}^{1}$, Dr. Kavitha BS ${ }^{2 *}$, Dr. Arifuddin $\mathrm{MK}^{2}$
}

${ }^{1}$ Associate Professor, Department of Physiology, Sri Siddhartha Medical College, Tumkur, India

${ }^{2}$ Assistant Professor, Department of Physiology, Sri Siddhartha Medical College, Tumkur, India

DOI: $10.36348 /$ sijap.2021.v04i03.004

| Received: 07.02.2021 | Accepted: 04.03.2021 | Published: 15.03.2021

*Corresponding author: Dr. Kavitha BS

\section{Abstract}

Background: Chalk board teaching as a medium of instruction in classroom is one of the most commonly used methods in lectures. In the recent past there is increased use of power point presentations which is now one of the most popular methods of delivering the lectures using electronic devices. In medical colleges chalk board teaching and PPT-based lectures are being used extensively and there is also a debate wherein the teaching faculty are divided in their opinion regarding the superiority of traditional chalk and talk method and PPT-based lectures. Objectives: To estimate the preferences of first year medical students between traditional chalk and talk lectures and PPT-based lectures. To assess the student perceptions about traditional chalk and talk lectures and PPT-based lectures. Methodology: A cross sectional study was carried out among 130 first year medical students of 2015-16 batches belonging to Sri Siddhartha Medical College Tumkur, Karnataka. A self structured questionnaire was administered to the study population and preferences of the students were estimated in percentage. Results: $66.15 \%$ (86) of the student preferred the traditional chalk and talk method over PPT-based lectures. 8.46\% (11) of the students preferred PPT-based lectures as a mode of teaching method citing that this technique offers them better quality of diagrams, pictures and sequence of images. 25.38\% (33) of students preferred the use of both the methods in the lecture wherein they feel that usage of black board to explain the key concept along with PPT-based lectures as a better method of teaching.

Keywords: Sectional Study of Perception Medical Students Teaching Methods.

Copyright (C) 2021 The Author(s): This is an open-access article distributed under the terms of the Creative Commons Attribution 4.0 International License (CC BY-NC 4.0) which permits unrestricted use, distribution, and reproduction in any medium for non-commercial use provided the original author and source are credited.

\section{INTRODUCTION}

The origin of lectures which are one of the commonest modes of teaching can be traced back to $5^{\text {th }}$ century BC among Greeks [1]. There is another school of thought among academicians who considers small group discussion as a better method of learning and conceptualizing [2].

Chalk board teaching as a medium of instruction in classroom is one of the most commonly used methods in lectures [3].

In the recent past there is increased use of power point presentations which is now one of the most popular methods of delivering the lectures using electronic devices [4].

Power point presentations are considered easy to use in classroom presentation [5]. There is data which is available on the web which says that there are around 20-30 million PPT-based lectures/presentations which are given each day around the globe.

In medical colleges chalk board teaching and PPT-based lectures are being used extensively and there is also a debate wherein the teaching faculty are divided in their opinion regarding the superiority of traditional chalk and talk method and PPT-based lectures [6].

Hence the present study was taken up among first year medical students belonging to 2015-16 batch of Sri Siddhartha Medical College to understand their perceptions and estimate their preferences between traditional chalk and talk method and PPT-based lectures.

\section{OBJECTIVES}

To estimate the preferences of first year medical students between traditional chalk and talk lectures and PPT-based lectures 
To assess the student perceptions about traditional chalk and talk lectures and PPT-based lectures

\section{MATERIALS AND METHODS}

A cross sectional study was carried out among 130 first year medical students of 2015-16 batch belonging to Sri Siddhartha Medical College Tumkur, Karnataka. Institutional ethical committee approval was taken for the conduct of the study. Informed consent for the study was taken from all the 130 study participants after explaining the need for the study. A self structured questionnaire was administered to the study population and preferences of the students were estimated in percentage. The perceptions of the students were recorded along with the questionnaire about the reason for their preference among the two teaching methods.

Confidentiality was maintained and the recorded responses were analyzed using Microsoft excel and Epi Info 7.

\section{RESULTS}

Table-1: Age and gender distribution of study population

\begin{tabular}{|l|l|l|}
\hline & Mean & Standard deviation \\
\hline Age of the subject & 18.07 & 0.62 \\
\hline Sex & Frequency & Percentage \\
\hline Female & 60 & 46.20 \\
\hline Male & 70 & 53.80 \\
\hline
\end{tabular}

Table-2: Preferences for each teaching method

\begin{tabular}{|l|l|l|}
\hline Lecture method & Frequency & Percentage \\
\hline Chalk and talk lectures & 86 & 66.15 \\
\hline PPT-based lectures & 11 & 8.46 \\
\hline Usage of Both & 33 & 25.38 \\
\hline
\end{tabular}

\section{DISCUSSION}

In our study $66.15 \%$ (86) of the student preferred the traditional chalk and talk method over PPT-based lectures. The results of our study are comparable to another study done by Novelli ELB and et al. was in most students' favored black board teaching [7]. The students who preferred chalk and talk method cite that this method allows them sufficient time to take down notes and diagrams and also feel that the natural pauses and breaks of the traditional lectures helps them to understand subject matter better. Few students also opine that their disliking for chalk board teaching is because of poor handwriting which is not legible on the board.

$8.46 \%$ [11] of the students preferred PPTbased lectures as a mode of teaching method citing that this technique offers them better quality of diagrams, pictures and sequence of images. The above mentioned findings of our study are in contrast with another study done by VikasSeth and et al. was in $65.33 \%$ of students preferred power point based lectures [8]. The study participants of our study opine that their dislike for PPT-based lectures is because of the fast delivery of lectures wherein they find it very difficult to take down notes and diagrams.

$25.38 \%$ (33) of students preferred the use of both the methods in the lecture wherein they feel that usage of black board to explain the key concept along with PPT-based lectures as a better method of teaching.

In another study done by ChaudryR and et al. among I MBBS medical students about two different visual aids in Physiology lectures reveals that majority of students $(61.1 \%)$ preferred the combined teaching aids [9].

In a study done by Baxi SN about student perception of teaching aids in a medical college revealed that equal number of students preferred traditional chalk board teaching and PPT-based lectures [10].

In a study done by Shallcross DE students agreed that the quality of the lecture depends upon the teacher who knows how to make them understand basic concepts in the study material and also lead them gradually towards understanding new and more complex topics [11].

\section{CONCLUSION}

The first year medical students who formed our study population prefer the use of chalk and talk methods of delivering of lectures over PPT-based lectures. Student's preferences can vary in their opinion regarding the choice of presentation of a lecture class. The previous literature which is available and the results of our study have varied choice of opinion of 
students regarding the mode of delivery with each having their own merits and demerits.

\section{RECOMMENDATIONS}

It is suggested that the teacher's should receive formal training in teaching as a trained and motivated teacher would make use of any teaching technique which is available and make the teaching learning experience enriching for his students.

\section{REFERENCES}

1. Vamshi, K. T., Datta, V. M., Kishan, Y. S. S., Aditya, V., \& Bhanuprakash, G. (2011). Comparative study on the teaching effectiveness of chalk \& talk and microsoft powerpoint presentation from the student perspective. International Journal of Pharmacy and Pharmaceutical Sciences, 4(1), 191-193.

2. Cannon, R. (1988). Lecturing, Kensington, NSW: Higher Education Research and Development Society of Australia.

3. Estes, A., Ressler, S., Welch, R., \& Hanus, J. (2009). Seminar on communication skills. In Exceed teaching workshop.

4. Prasad, S., Roy, B., \& Smith, M. (2000). The art and science of presentation: electronic presentations. Journal of postgraduate medicine, 46(3), 193.
Pedras, M. J., \& Horton, J. (1996). Using Technology to Enhance Teacher Preparation.

5. Amare, N. (2006). To slideware or not to slideware: Students' experiences with PowerPoint vs. lecture. Journal of technical writing and communication, 36(3), 297-308.

6. Novelli, E. L., \& Fernandes, A. A. H. (2007). Students' preferred teaching techniques for biochemistry in biomedicine and medicine courses. Biochemistry and Molecular Biology Education, 35(4), 263-266.

7. Seth, V., Upadhyaya, P., Ahmad, M., \& Moghe, V. (2010). PowerPoint or chalk and talk: Perceptions of medical students versus dental students in a medical college in India. Advances in medical education and practice, 1,11 .

8. Choudhary, R., Dullo, P., \& Gupta, U. (2009). Attitude of 1st MBBS medical students about two different visual aids in physiology lectures. Pakistan Journal of Physiology, 5(2), 1619.

9. Baxi, S. N., Shah, C. J., Parmar, R. D., Parmar, D., \& Tripathi, C. B. (2009). Students' perception of different teaching aids in a medical college. African Journal of health professions education, 1(1), 1516.

10. Shallcross, D. E., \& Harrison, T. G. (2007). Lectures: electronic presentations versus chalk and talk-a chemist's view. Chemistry Education Research and Practice, 8(1), 73-79. 